\title{
Binding neutral information to emotional contexts: Brain dynamics of long-term recognition memory
}

\author{
Carlos Ventura-Bort ${ }^{1,2} \cdot$ Andreas Löw ${ }^{1,3} \cdot$ Julia Wendt $^{1} \cdot$ Javier Moltó $^{2} \cdot$ Rosario Poy $^{2}$. \\ Florin Dolcos $^{4}$ • Alfons O. Hamm ${ }^{1}$ - Mathias Weymar ${ }^{1}$
}

Published online: 3 November 2015

(C) Psychonomic Society, Inc. 2015

\begin{abstract}
There is abundant evidence in memory research that emotional stimuli are better remembered than neutral stimuli. However, effects of an emotionally charged context on memory for associated neutral elements is also important, particularly in trauma and stress-related disorders, where strong memories are often activated by neutral cues due to their emotional associations. In the present study, we used event-related potentials (ERPs) to investigate long-term recognition memory (1-week delay) for neutral objects that had been paired with emotionally arousing or neutral scenes during encoding. Context effects were clearly evident in the ERPs: An early frontal ERP old/new difference (300$500 \mathrm{~ms}$ ) was enhanced for objects encoded in unpleasant compared to pleasant and neutral contexts; and a late centralparietal old/new difference (400-700 ms) was observed for objects paired with both pleasant and unpleasant contexts but not for items paired with neutral backgrounds. Interestingly, objects encoded in emotional contexts (and
\end{abstract}

novel objects) also prompted an enhanced frontal early (180-220 ms) positivity compared to objects paired with neutral scenes indicating early perceptual significance. The present data suggest that emotional-particularly unpleasantbackgrounds strengthen memory for items encountered within these contexts and engage automatic and explicit recognition processes. These results could help in understanding binding mechanisms involved in the activation of trauma-related memories by neutral cues.

Keywords Event-related potentials $\cdot$ ERPs $\cdot$ Emotion $\cdot$ Context $\cdot$ Relational memory $\cdot$ Associative memory $\cdot$ Old/New effect $\cdot$ Recognition

There is considerable evidence that emotions play a critical modulatory role in episodic memory (Dolcos, Denkova, \& Dolcos, 2012; Weymar \& Hamm, 2013). For instance,
Carlos Ventura-Bort

cventura@uji.es

Mathias Weymar

mathias.weymar@uni-greifswald.de

Andreas Löw

loew@hsu-hh.de

Julia Wendt

julia.wendt@uni-greifswald.de

Javier Moltó

molto@uji.es

Rosario Poy

poy@uji.es

Florin Dolcos

fdolcos@illinois.edu
Alfons O. Hamm

hamm@uni-greifswald.de

1 Department of Biological and Clinical Psychology, University of Greifswald, Franz-Mehring-Str. 47, 17487 Greifswald, Germany

2 Department of Basic and Clinical Psychology, and Psychobiology, Universitat Jaume I, Av. Sos Baynat unnumbered, 12071 Castellón, Spain

3 Department of Humanities and Social Sciences, HelmutSchmidt-University/University of the Federal Armed Forces Hamburg, 700822, Hamburg 22008, Germany

4 Psychology Department, Neuroscience Program, Beckman Institute for Advanced Science and Technology, University of Illinois at Urbana-Champaign, Champaign, IL, USA 
when presenting emotional and neutral materials, and memory is subsequently tested, emotionally arousing items are better remembered and are more robust against forgetting than emotionally neutral items (e.g., Bradley, Greenwald, Petry, \& Lang, 1992; Dolcos, LaBar, \& Cabeza, 2005; Weymar, Löw, \& Hamm, 2011; Wirkner, Löw, Hamm, \&Weymar, 2015). Despite convincing evidence for a memory-enhancing effect of emotion, neutral cues can also activate strong emotional memories (e.g., in patients suffering from trauma or stress-related disorders) if these events were associated with an emotional context in which these items were encountered during encoding (e.g., Davachi, 2006; Ranganath, 2010). To understand how emotion interacts with these real-world situations, recent research has therefore focused on the emotion's effects on memory for items as a part of, or in relation to other items, the so-called contextual relational binding (Chiu, Dolcos, Gonsalves, \& Cohen, 2013). Here, we investigated the brain dynamics of contextual/relational memory using event-related potentials (ERPs) recorded during retrieval.

It is a robust finding in memory research that ERPs generated by correctly recognized old stimuli evoke more positive-going waveforms than those elicited by correctly detected new stimuli (for reviews, see Rugg \& Curran, 2007; Weymar \& Hamm, 2013). This difference in ERP positivity has been labeled the ERP old/ new effect. Two ERP old/new differences have been identified reflecting different processes involved in recognition memory: An early old/new effect (300-500 ms) located over frontal brain regions has been related to acontextual familiarity-based remembering, while centroparietal old/new differences $(>500 \mathrm{~ms})$ have been associated with recollection-based remembering (i.e., retrieval of specific contextual information about the learning episode; Rugg \& Curran, 2007; Weymar \& Hamm, 2013). ERP studies exploring the electrophysiological correlates of long-lasting enhancing memory effects of emotion showed that emotional events, compared to neutral ones, are associated with larger old/new effects over parietal areas (e.g., Jaworek, Weymar, Löw, \& Hamm, 2014; Schaefer, Pottage, \& Rickart, 2011; Weymar, Löw, Melzig, \& Hamm, 2009; Weymar et al., 2011; Weymar, Löw, Modess, et al., 2010a; Weymar, Löw, Schwabe, \& Hamm, 2010b; Wirkner et al., 2015; Wirkner, Weymar, Löw, \& Hamm, 2013), suggesting that remembering of emotional events is most likely guided by recollection, rather than familiarity (Dolcos et al., 2005).

The few available behavioral and ERP studies investigating the effect of emotion on memory for associated contextual information, however, have produced mixed results. Some researchers found better memory for contextual features of emotional items (e.g., Doerksen \& Shimamura, 2001; Mather \& Nesmith, 2008; Nashiro \& Mather, 2011) and neutral items embedded in arousing contexts (e.g., Guillet \& Arndt, 2009; Pierce \& Kensinger, 2011), whereas others found impairments in memory performance (e.g., Bisby \& Burgess, 2014; Nashiro \& Mather, 2011; Rimmele, Davachi, Petrov, Dougal, \& Phelps, 2011; Touryan, Marian, \& Shimamura, 2007) or no effects (e.g., Koenig \& Mecklinger, 2008; Sharot \& Phelps, 2004) when retrieving emotional, relative to neutral, contextual source information (e.g., paired words, background scenes or features). Smith, Dolan, and Rugg (2004) explored ERPs related to immediate recognition of emotionally neutral objects associated with emotional and nonemotional background scenes. These authors found no ERP old/ new differences between context categories in early frontal or late parietal regions (replicated by Jaeger, Johnson, Corona, \& Rugg, 2009). Similarly, Maratos and Rugg (2001) also did not observe ERP old/new differences when source information (contextual pairings) was tested for neutral words encoded in emotionally arousing sentences compared to emotionally neutral sentences. Hence, compared to ERP results from episodic memory studies using single items, ERP findings related to relational memory seem to indicate no emotional modulation in contextual memory processes.

One potential contributing factor for the lack of emotional effects might be the length of the retention interval (for discussion concerning item memory, see Weymar \& Hamm, 2013). Most available studies have used immediate testing but emotional advantages in single-item memory have often been augmented over time, in part by facilitating consolidation processes (e.g., Quevedo et al., 2003; McGaugh, 2004; LaBar \& Cabeza, 2006; Ritchey, Dolcos, \& Cabeza, 2008). For delayed intervals, greater memory accuracy (Weymar \& Hamm, 2013), stronger recollective experience, and larger ERP old/new differences have been reported for emotionally arousing stimuli (Schaefer et al., 2011; Sharot, Delgado, \& Phelps, 2004; Weymar et al., 2010b), especially for unpleasant events (Weymar et al., 2011). Thus, emotion might also facilitate contextual or relational binding after a longer delay (as suggested by Pierce \& Kensinger, 2011). In accordance with this suggestion, in behavioral research it has been observed that recognition of emotional contextual cues compared to neutral ones is enhanced after long (such as 1 or 7 days), but not after short delays (Pierce \& Kensinger, 2011; Sharot \& Phelps, 2004). Recently, two ERP studies have investigated emotional contextual binding (Jaeger et al., 2009; Jaeger \& Rugg, 2012) on a 
delayed test (24 hours). However, Jaeger and colleagues found no better memory for neutral objects encoded in emotionally unpleasant background scenes compared to those neutral objects associated with neutral scenes, indicating that beneficial effects of contexts may occur after longer consolidation periods (c.f., Pierce \& Kensinger, 2011)

One other important factor to be considered in emotional relational memory is the manner in which stimuli are bound (MacKay, Shafto, Taylor, Marian, Abrams, \& Dyer, 2004; Mather, 2007). According to the arousalbiased competition (ABC) theory (Mather \& Sutherland, 2011), emotional arousal can lead to enhancement and impairment among neutral stimuli competing for attention, depending on high or low priority (due to bottom-up perceptual salience or top-down attentional focus). The theory further suggests that emotional arousal may enhance associative memory for features of high priority items (e.g., color or location of an item) and impair memory for neutral items, when presented at the same time with emotional items. However, if the association between emotional cues and neutral items is well integrated, memory for neutral items may improve due to the acquisition of high priority. In order to prevent competition between emotional and neutral stimuli, in the current study participants were instructed to imagine the object as a part of the scene to promote the binding between object and background (cf. Awipi \& Davachi, 2008). Moreover, unlike prior studies (e.g., Smith, Dolan, et al., 2004; Jaeger \& Rugg, 2012), in which objects were presented visually separated from the background scenes (e.g., surrounded with white background and yellow frame), objects were unframed and presented with transparent background to further facilitate object/context integration. Finally, objects were presented first, followed by the background scene, to avoid direct competition between emotional backgrounds and neutral objects, as it might occur when the emotional stimulus is introduced first (cf. Jaeger \& Rugg, 2012).

Thus, to further investigate the role of emotion on context binding, we explored electrophysiological correlates of recognition memory for neutral events embedded in emotional contexts, taking into account various critical factors facilitating emotional context memory (i.e., delayed retention interval and event-context integration). Furthermore, some memory studies (e.g., Bradley et al., 1992; Dolcos et al., 2005; Weymar et al., 2009) found that emotionally arousing stimuli are better remembered than low arousing neutral stimuli, observing no differences in the retrieval of unpleasant and pleasant material, whereas others observed a preference in remembering negative information over positive and neutral information (e.g., for associative memory, see Pierce \& Kensinger, 2011; for item memory, see Weymar et al., 2011). In order to explore the effects of arousal and emotional valence on memory binding in healthy individuals, both high arousing pleasant and unpleasant pictures were included as contexts in the present study.

The experimental procedure consisted of two phases (see Smith, Dolan, et al., 2004, for a similar design): An incidental encoding task where emotionally neutral objects were presented in the context of emotionally neutral or emotionally arousing background scenes; and a recognition memory task in which item (old vs. new) and context (pleasant vs. unpleasant vs. neutral background picture) was tested. Based on previous studies reporting memory enhancing-effects in the context of emotion (e.g., Guillet \& Arndt, 2009; Pierce \& Kensinger, 2011), we made a first prediction concerning behavioral performance: (a) we expected that objects encoded in emotional contexts would be better remembered than objects encoded in neutral contexts after a 1week retention interval. Concerning associated brain dynamics we made a second prediction: (b) we expected to find larger parietal ERP old/new differences (500$700 \mathrm{~ms}$ ) for neutral objects previously paired with emotional, relative to neutral background pictures, possibly reflecting explicit recollection.

\section{Materials and method}

\section{Participants}

Participants were 30 healthy students (26 women, 4 men; mean age $=22.7$ years; 3 left-handed, 27 righthanded) from the University of Greifswald, with normal or corrected-to-normal vision, who participated for course credits or financial compensation. All participants were native German speakers. Each individual provided written informed consent for a protocol approved by the Review Board of the German Psychological Society (DGPs). Data from three participants were excluded due to excessive artifacts in the electroencephalogram (EEG) data.

\section{Stimulus materials}

A total of 288 neutral objects and 144 background scenes were used in the present experiment. Neutral objects were selected from two different standardized sets: The Bank of Standardized Stimuli (BOSS; Brodeur, Dionne-Dostie, 
Montreuil, \& Lepage, 2010) and the ecological adaptation of Snodgrass and Vanderwart (Moreno-Martínez \& Montoro, 2012). ${ }^{1}$ Objects belonged to a variety of different semantic categories (e.g., office supplies, electronics, household objects) and were grouped in six different sets carefully matched in terms of semantic category, familiarity, object agreement, and manipulability, according to the normative ratings of the standard samples (see BOSS and ecological adaptation of Snodgrass and Vanderwart norms). Background scenes were selected from the International Affective Picture System (IAPS; Lang, Bradley \&

\footnotetext{
${ }^{1}$ 1BOSS: bib, clamp, headphones $02 \mathrm{~b}$, mallet $01 \mathrm{~b}$, powercable, bottlecap, calculator01, cookiecutter, flask, makeupbrush04, nailpolish03b, pictureframe 04, razor01, scotchtape, tennisball01b, circuitboard, pacifier02d, whee101, bracket01, beermug01a, nail, strainer02, chalkboard, log, petcarrier, dustpan, giftbag01a, plunger02, studiolight, balloon01b, cane, globe, jar02, chessboard, hanger02a, pitcher02b, ring01, swimgoggles, iron $01 \mathrm{~b}$, mitten 04 , tripod, electricrazor, lego03b, tshirt, CD, hinge, highheelshoe01, rearviewmirror, wallet02a, boxcutter03a, cottonpad, envelope03a, glass02a, horsefigurine, leaf02a, match, screwdriver04b, sunglasses 04 , walkman, medal02b, watch02a, rope 03 , bag, coffeepot03a, plate01b, flyswatter, microscope, pillow01a, vase 02 , cooler, kettle01, notebook03a, pylon, oilbottle01, laptop01a, clothespin03b, eraser, divider02, violin, number3, scale01a, videocamera01a, speaker04, lunchbox, cigarette, corkscrew03a, carkeys, key01, mixer01d, starfish, toothbrush03b, remotecontrol04, camera01a, holepunch04, reflector, waterbottle $01 \mathrm{~b}$, bandaid01, bracelet 01 , cell phone, diaper01c, hosenozzle, paperclip01b, pingpongracket, thimble, tweezers $02 \mathrm{a}$, hourglass, scissors 01 , tile, manshoe, folder03a, milkcontainer, wateringcan, bikehelmet, fan, sewingmachine01a, tambourine, plasticgallon, papertowel, kitchenscale $01 \mathrm{a}$, broom, candle $08 \mathrm{~b}$, playingcard04, toycow, exercisebench, comb02a, kleenexbox01b, sock01a, alarmclock, fork $03 \mathrm{c}$, icecubetray $01 \mathrm{a}$, peeler01, sponge 01 , basebal101a, chain, dice05a, filmroll, gluestick, lighter01, pen04b, stapler03a, taperecorder, thread02, wrench01b, pencilsharpener02a, lock03a, tongs01b, glassmop, keyboard02, printer02, bleachbottle, hairdryer02a, wood, axe, drill01b, fireextinguisher, lamp04a, teapot, winerack, plant01, fishinghook03, teabag, foodprocessor, plasticbasket01a, lifejacket, suitcase, propanetank, pinecone01, monitor, painttray, visegrippliers, brush05b, mousetrap, thermometer02b, cassettetape $01 \mathrm{a}$, handfan $01 \mathrm{~b}$, peppermill02b, spoon01, whisk, bubbleblower, chisel02b, compactpowder, diskette02a, hairclip03, lipstick02a, pliers02b, safetypin, stapleremover, thumbtack02a, usbkey, belt02a, staples, vikingmask01b, antenna, spraybottle01, bow101, ridinghelmet, babyseat, boot $02 \mathrm{~b}$, drum, pants, sportbag, toaster, cardboardbox, squeegee 01b, earrings01, glasses01a, cameracase $01 \mathrm{a}$, babybottle, pot02a, chair, binder03b, dropper, umbrella04, icepack, battery $02 \mathrm{~b}$, chalkboarderaser, hat $03 \mathrm{~b}$, magnifyingglass $01 \mathrm{~b}$, plugs, spraycan, 50dollarsbill, birdie, bungeecord02, christmasball, computermouse 06 , flashlight $02 \mathrm{~b}$, highlighter02b, keychain, nailclipper03b, perfume $01 \mathrm{a}$, puzzlepiece, telephone $01 \mathrm{~b}$, toiletpaper01a, bucket01a, saw02b, handbag02a, radio01, scarf, paintroller01, strawbasket01, backpack01a, clipboard, fryingpan02a, iceskate, rollingpin01a; the ecological adaptation of Snodgrass and Vanderwart: chest of drawers, skirt, saxophone, harp, diabolo, bedside table, skate, rocking chair, clarinet, saucepan, skittle, wardrobe, ludo, undershirt, racket, balalaika, trumpet, bathrobe, trowel, bed, couch, showel, coat, bugle, stool, chair, biretta, piano, soccer ball, sofa, filling cabinet, dartboard, table, ski, drum, fondue, guitar, tuba, jacket, accordion, armchair, bookcase, table football.
}

Cuthbert, 2008), consisting of 48 pleasant (e.g., erotic, adventure, babies, small animals), 48 neutral (e.g., buildings, landscapes, neutral human faces), and 48 unpleasant (e.g., mutilation, attack, disgust, accident) pictures. ${ }^{2}$ Mean $(S D)$ valence and arousal ratings (respectively) for the three picture valence categories were as follows: Pleasant: 6.94 (0.63), 5.84 (0.77); neutral: $5.27(0.82)$, 3.51 (0.57); and unpleasant: $2.73(0.85), 5.93(0.57)$. Pleasant, neutral and unpleasant pictures did not differ in complexity, brightness, and contrast (all $p \mathrm{~s}>.23$ ).

During encoding, neutral objects were presented superimposed on an emotional or neutral background scene. Participants were presented with one of six encoding lists (for list construction, see Jaeger et al., 2009; Smith, Dolan, et al., 2004), each consisting of 144 object/background pairs, with no more than two pictures from the same valence presented consecutively. Each neutral object set was paired with a neutral background scene in one list, an unpleasant background in another, a pleasant background scene in a third, and was available as a novel object set for the remaining three lists.

\section{Procedure}

During encoding, 144 objects were superimposed on 144 background scenes. Objects (mean vertical and horizontal visual angle of $4.96^{\circ}$ ) and background scenes (vertical visual angle of $7.73^{\circ}$, horizontal visual angle of $10.93^{\circ}$ ) were presented on a 20 -in. computer monitor located $150 \mathrm{~cm}$ in front of the participant. In contrast to previous studies (e.g., Jaeger et al., 2009; Jaeger \& Rugg, 2012; Smith, Dolan, et al., 2004, Smith, Henson, Dolan, \& Rugg, 2004; Smith, Henson, Rugg, \& Dolan, 2005), in which objects were visually separated (white background and/or yellow frame), here objects were presented with transparent background and without frame to facilitate object-scene binding. Objects were presented in one of four quadrants of the screen. The four positions of the objects were selected randomly and with the same probability for each background category. After 3,000 ms, an emotional or neutral scene was added as background. Each

\footnotetext{
${ }^{2}$ Pleasant pictures: 1440, 1590, 1640, 1650, 1659, 1811, 2035, 2045, 2075, 2158, 2160, 2165, 2208, 2340, 2345, 4598, 4599, 4604, 4643, 4645, 4647, 4658, 4659, 4660, 4680, 4687, 4690, 4694, 4800, 5470, $5621,5626,8001,8030,8041,8080,8158,8170,8186,8191,8192$, $8206,8211,8260,8300,8470,8490$, and 8620 ; neutral pictures: 2026, 2038, 2039, 2102, 2104, 2190, 2206, 2211, 2273, 2359, 2377, 2383, $2390,2410,2511,2513,2595,2840,2850,5201,5390,5510,5535$, 5593, 5711, 5836, 5875, 5982, 7033, 7037, 7041, 7130, 7161, 7179, 7205, 7234, 7491, 7495, 7504, 7510, 7546, 7550, 7590, 7595, 7620, 7920, 9210, and 9469; unpleasant pictures: 1019, 1026, 1205, 1220, 1302, 1931, 1932, 3015, 3019, 3051, 3064, 3100, 3102, 3110, 3150, $3180,3181,3190,3191,3195,3280,3530,6212,6370,6410,6560$, $6562,6563,6571,6832,8480,9008,9042,9230,9253,9301,9420$, 9490, 9520, 9561, 9570, 9599, 9622, 9635.1, 9908, 9910, 9921, and 9930.
} 
object and scene pairing was presented for 5,000 ms with an intertrial interval (ITI) of 3,000, 3,500, or $4,000 \mathrm{~ms}$. The encoding phase was separated into two blocks in which all 144 object-scene pairings were presented and after a break of 1 minute, the exact 144 same object/scene pairings were repeated (but in randomized order). Participants were instructed to imagine that the object is a part of the scene and to indicate after object/scene offset whether the imagination was successful or not by pressing a "yes" or a "no" button on a response pad (see Fig. 1). No mention of a memory test was made (incidental encoding).

One week after encoding, participants returned to the lab for a memory task, in which old and new objects were presented. The task took place in a sound-attenuated dimly lit room. Each participant viewed 288 objects (i.e., 144 old and 144 novel objects). Of the 144 old objects, 48 objects had been encoded in the context of an unpleasant scene, 48 objects in the context of a pleasant scene, and 48 objects in the context of a neutral scene. Each object was presented in the center of the screen (mean vertical and horizontal visual angle of $5.92^{\circ}$ ) without context for 3,000 ms with a preceding fixation cross of $500 \mathrm{~ms}$.

Participants were instructed to decide whether each object had previously been seen during encoding or not. Following object offset, ${ }^{3}$ the question "Old/New?" appeared on the screen, and participants pressed the "old" button on a keyboard if they remembered the object or else the "new" button. When the object was recognized as old, subjects were asked to remember source information cues: the location the object was presented at during encoding (i.e., which quadrant of the screen) and the background paired with it (i.e., pleasant, neutral, or unpleasant; see Fig. 1). Participants were instructed to avoid eye blinks and body movements.

\section{Apparatus and data analysis}

EEG signals were recorded continuously from 257 electrodes using an Electrical Geodesics (EGI) HydroCel high-density EEG system with NetStation software on a Macintosh computer. The EEG recording was digitized at a rate of $250 \mathrm{~Hz}$, using vertex sensor $(\mathrm{Cz})$ as recording reference. Scalp impedance for each sensor was kept below $30 \mathrm{k} \Omega$, as recommended by manufacturer guidelines. All channels were band-pass filtered online from 0.1 to $100 \mathrm{~Hz}$. Offline reduction was performed using ElectroMagnetic EncephaloGraphy Software (EMEGS; Peyk, De Cesarei, \& Junghöfer, 2011) and included low-pass filtering at $40 \mathrm{~Hz}$, artifact detection, sensor interpolation, baseline correction, and conversion to the average reference (Junghöfer, Elbert, Tucker, \& Rockstroh, 2000). Stimulus-synchronized epochs were extracted from $100 \mathrm{~ms}$ before to $1,200 \mathrm{~ms}$ after

\footnotetext{
${ }_{3}^{3}$ Behavioral recognition responses were delayed until offset of the 3-s picture presentation in order to avoid contamination by motor potentials. Reaction times are therefore not informative and were not analyzed.
}

picture onset and baseline corrected (100 ms prior to stimulus onset). Extracted epochs were corrected for eye movement and blink artifacts using the MATLAB-based toolbox BioSig (Vidaurre, Sander, \& Schlögl, 2011).

For each participant, separated ERP averages were computed for each sensor and condition. Only trials with correct responses for old and new objects were included in ERP averages. Due to the low number of hits in the source memory task (location and background), only ERPs during the item recognition task (old vs. new) were analyzed. The identification of sensor clusters representative for maximal old/new effects were based on visual inspection of the waveforms and based on previous studies (Jaeger et al., 2009; Jaeger \& Rugg, 2012; Maratos \& Rugg, 2001; Smith, Dolan, et al., 2004; Weymar et al., 2009, 2010b; Weymar, Löw, Modess, et al. 2010a; Wirkner et al., 2013, 2015). Because recent studies observed context effects at earlier ( $<300 \mathrm{~ms}$ ) stages of processing (Curran \& Dien, 2003; Tsivilis, Otten, \& Rugg, 2001; Voss \& Paller, 2009), especially for emotionally arousing events (Jaeger et al., 2009; Jaeger \& Rugg, 2012; Schaefer et al., 2011; Smith, Dolan, et al., 2004), we also examined ERP differences in an early time window. Mean ERP amplitudes were analyzed in a 180 to $220 \mathrm{~ms}$ and 300 to $500 \mathrm{~ms}$ time window over frontal brain regions (EGI HydroCel sensors $5,6,7,8,14,15,16,22,23$, and 29), and in a 400 to $700 \mathrm{~ms}$ time window over centro-parietal brain regions (EGI HydroCel sensors 9, 45, 80, 81, 89, 90, 130, 131, 132, 186, and 257). Recognition-related ERP data for each time window were analyzed in two separate ANOVAs, including the factors Memory (old objects vs. new objects) and Context (neutral objects encoded in pleasant contexts vs. neutral contexts vs. unpleasant contexts). If there was no difference between objects encoded in pleasant and unpleasant contexts, an ANOVA with the factor Emotion (neutral objects encoded in pleasant and unpleasant contexts vs. neutral context) was performed.

For behavioral performance data, hit rate was analyzed using an ANOVA involving the factor Context (objects encoded in pleasant context vs. neutral context vs. unpleasant context). For the source task, hit rates for stimulus location (hit location/ hit old object) and background recognition (hit context/hit old object) were analyzed in separate ANOVAs involving the factor Context. Again, if pleasant and unpleasant contexts did not differ, an ANOVA with the factor Emotion (objects encoded in emotional context vs. neutral context) was performed. For effects involving repeated measures, the Greenhouse-Geisser correction for nonsphericity was used when necessary.

\section{Results}

\section{Behavioral data}

Memory performance for old (item and source memory data) and new objects is listed in Table 1. 

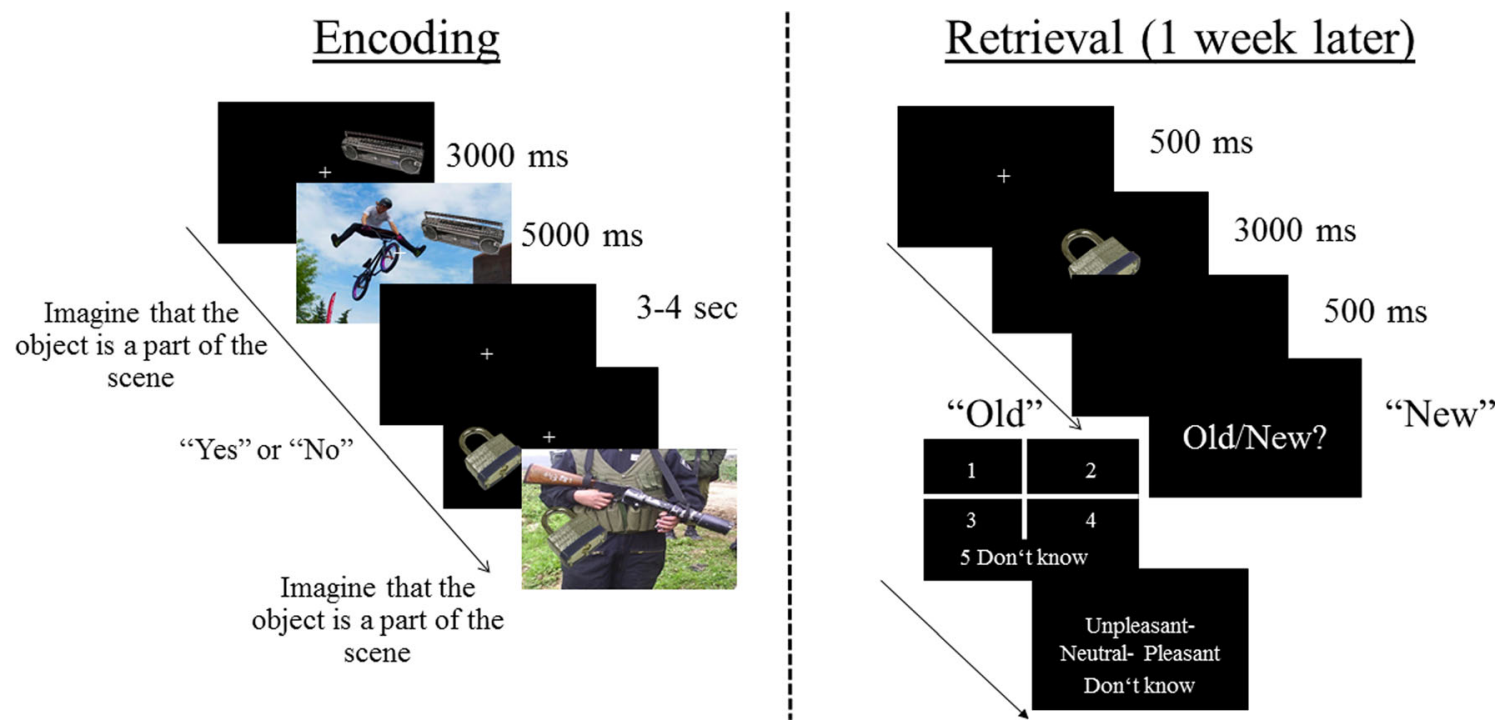

Fig. 1 Schematic view of the stimulus presentation during encoding and retrieval

Item memory Hit rates for objects previously paired with emotional pictures tended to be higher than for objects encoded in a neutral context, Emotion: $t(29)=1.96, p=.059, d=.19$. No differences were found between hit rates for objects that had been paired with pleasant and unpleasant backgrounds, $t(29)=$ $1.08, p=.28, d=.13$, suggesting that memory for neutral objects benefits from binding with emotionally arousing contexts irrespective of their valence during encoding.

Source accuracy rates Hit rates for remembered objects location were low and similar for emotional and neutral contexts $(F$ $<1$ ), indicating that emotional context did not influence memory for source location. Overall, correct source memory for background pictures was low, and did not differ from the probability of guessing, that is, from the proportion of randomly choosing a correct contextual source $(.33 ; p s>.286)$. However, there were differences as a function of picture content, Context: $F(2,58)=$ $10.37, p<.001, \eta_{\mathrm{p}}{ }^{2}=.26$. Unpleasant, $F(1,29)=5.13, p<.05$, $\eta_{\mathrm{p}}{ }^{2}=.15$, and neutral, $F(1,29)=19.9, p<.001, \eta_{\mathrm{p}}{ }^{2}=.41$, contexts were better classified than pleasant contexts. Recognition for correct background also differed for unpleasant and neutral scenes, $F(1,29)=5.5, p<.05, \eta_{\mathrm{p}}{ }^{2}=.16$. The probability of committing a false alarm by mistakenly identifying a context as neutral (.53) significantly differed from the chance level, $t(29)=5.8, p<.001$, and from the probability of erroneously identifying a context as pleasant, $.4 ; t(29)=3.6, p<.001, d$ $=.63$, and unpleasant, $.4 ; t(29)=3.59, p<.001, d=.63$, indicating a response bias toward neutral contexts. Based on the assumption that the response bias is a good estimate of the bias operating for object recognition, Maratos and Rugg (2001) suggest that the probability of recollection of context information can be obtained from the following formula: $p$ Correct source $=$ $p$ Recollection $+p$ Guess $\times(1-p$ Recollection $)$. After applying the formula, the probabilities of correct background recognition were higher for pleasant (.77) and unpleasant (.76) compared to neutral contexts $(.74)$, in accordance with the item memory performance.

\section{ERP encoding data}

To exclude a priori object differences, we compared ERPs in response to neutral objects subsequently encoded in emotional
Table 1 Hit rate means (standard deviation) for new and old objects encoded in pleasant, neutral, and unpleasant contexts.

\begin{tabular}{llll}
\hline & \multicolumn{1}{l}{ Hit rates } & \\
\cline { 2 - 4 } & Item recognition & Source location & Source background \\
\hline New objects & $.93(.04)$ & & \\
Old objects & & & $.25(.13)$ \\
$\quad$ Pleasant context & $.65(.14)$ & $.13(.09)$ & $.36(.20)$ \\
Neutral context & $.62(.15)$ & $.12(.08)$ & $.30(.16)$ \\
Unpleasant context & $.64(.14)$ & $.14(.10)$ & $.27(.14)$ \\
Emotional context & $.13(.08)$ & & \\
\hline
\end{tabular}

${ }^{a}$ Combining pleasant and unpleasant contexts 


\section{Frontal ERP Effect}

a

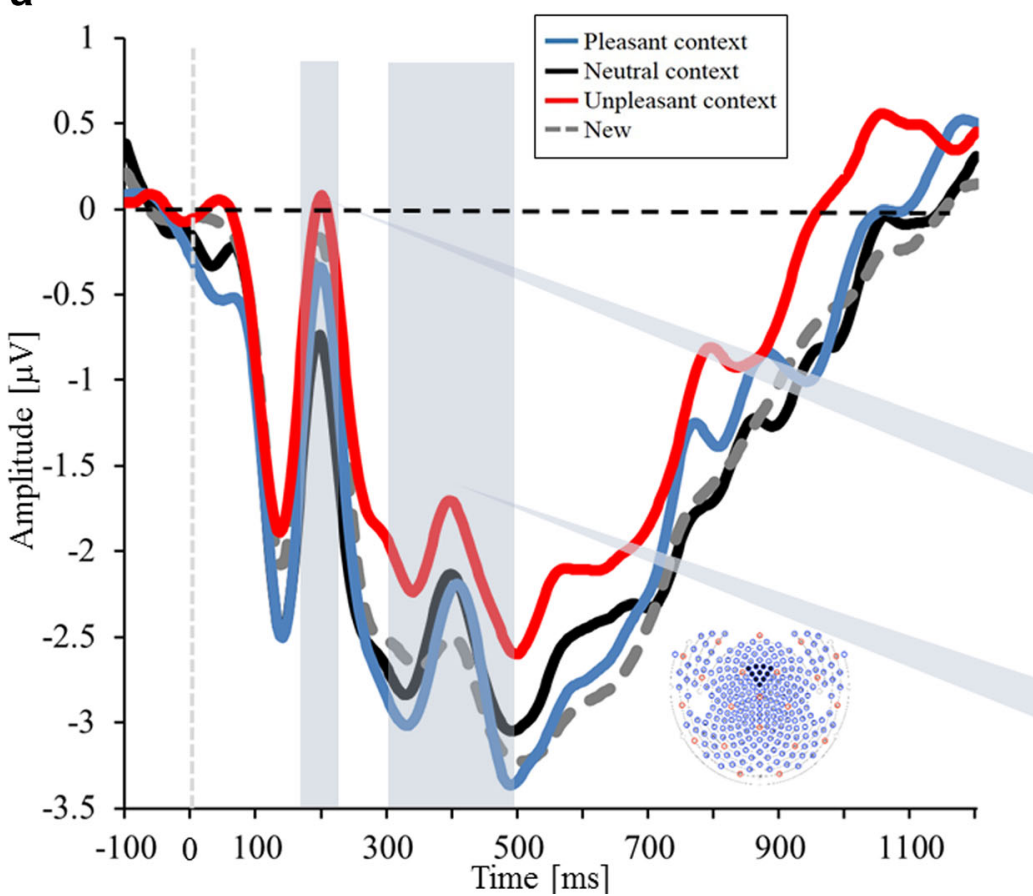

b Objects encoded in unpleasant contexts

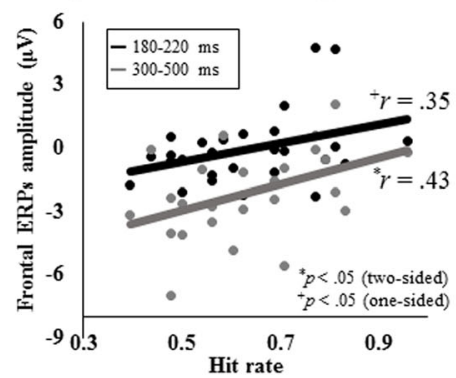

C Scalp Differences

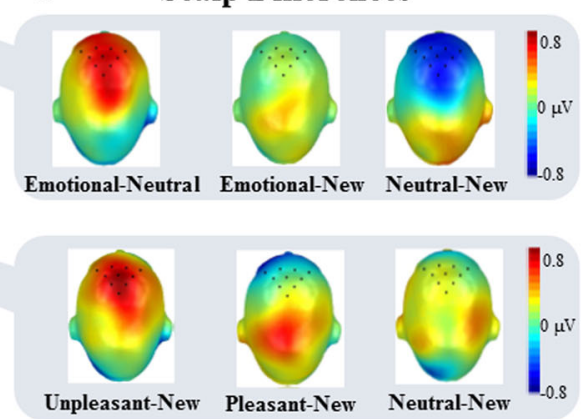

Fig. 2 Frontal ERP Effect. A: Grand average ERPs in response to correctly recognized new (gray dotted line) and old objects encoded in pleasant (blue line), neutral (black line), and unpleasant (red line) contexts. ERPs are averaged across electrodes within a frontal sensor cluster. B: Correlations between the mean amplitude of the frontal ERPs positivity at $180-220 \mathrm{~ms}$ (black line) and 300-500 ms (gray line)

or neutral context in the first block of the encoding session. No ERP differences were found at any time window or sensor location $(F<1)$.

\section{ERP recognition data}

Frontal ERP effect Figure 2A illustrates the grand average ERPs extracted from the frontal cluster for old objects previously encoded in the context of a pleasant, neutral, and unpleasant scene and new objects.

Early ERP Emotional effect (180-220 ms) For the early time window, no ERP old/new difference was found (Memory: $F<1$ ). However, frontal positivity in the time window between 180 and $220 \mathrm{~ms}$ was modulated by context, $F(2$, $52)=3.83, p<.05, \eta_{\mathrm{p}}{ }^{2}=.13$. Follow-up testing showed that objects previously paired with emotional pictures prompted a larger positivity than objects paired with neutral pictures, Emotion: $F(1,26)=4.17, p=.05, \eta_{\mathrm{p}}{ }^{2}=.14$ (see Fig. 2C). No significant ERP differences were found between objects paired with unpleasant scenes compared to objects paired with pleasant scenes, $F(1,26)=3.2, p=.09, \eta_{\mathrm{p}}{ }^{2}=.09$. When comparing new objects with old objects from different encoding contexts, we observed that novel objects also time window, and hit rate for objects encoded in unpleasant contexts. C: Display of the scalp topographies of the ERP differences. The upper scalp differences plot the early (180-200 ms) emotional ERP effects; the lower topographies represent the ERP old/new effect at 300-500 ms. (Color figure online)

produced a larger ERP positivity than objects previously encoded in neutral contexts, $F(1,26)=4.96, p<.05, \eta_{\mathrm{p}}{ }^{2}=.16$.

Early ERP Old/New effect (300-500 ms) ERPs for old objects were modulated by Context, $F(1,52)=3.81, p<.05, \eta_{\mathrm{p}}^{2}$ $=.13$. Enhanced positivity was found for objects previously paired with unpleasant contexts, compared to pleasant, $F(1$, 26) $=8.54, p<.01, \eta_{\mathrm{p}}{ }^{2}=.25$, and neutral contexts, $F(1,26)=$ $4.09 p=.05, \eta_{\mathrm{p}}{ }^{2}=.14$. Although the main effect of memory was not significant, Memory: $F(1,26)=1.55, p=.22, \eta_{\mathrm{p}}{ }^{2}=$ .05 , only objects from unpleasant backgrounds showed a significant old/new effect: unpleasant contexts vs. new objects, $F(1,26)=8.58, p<.01, \eta_{\mathrm{p}}{ }^{2}=.25$. Objects paired with pleasant and neutral backgrounds did not show such an old/new difference $(F<1$; see Fig. $2 \mathrm{C})$.

Parietal ERP effect Figure 3A illustrates the grand average ERPs for correctly recognized neutral objects encoded in the context of a pleasant, neutral, or unpleasant scene, and for new objects from a representative centro-parietal cluster.

Late ERP Old/New effect (400-700 ms) As expected, correctly recognized old objects elicited a larger positive-going waveform than correctly detected new objects, Memory: $F(1$, 


\section{Parietal ERP Effect}

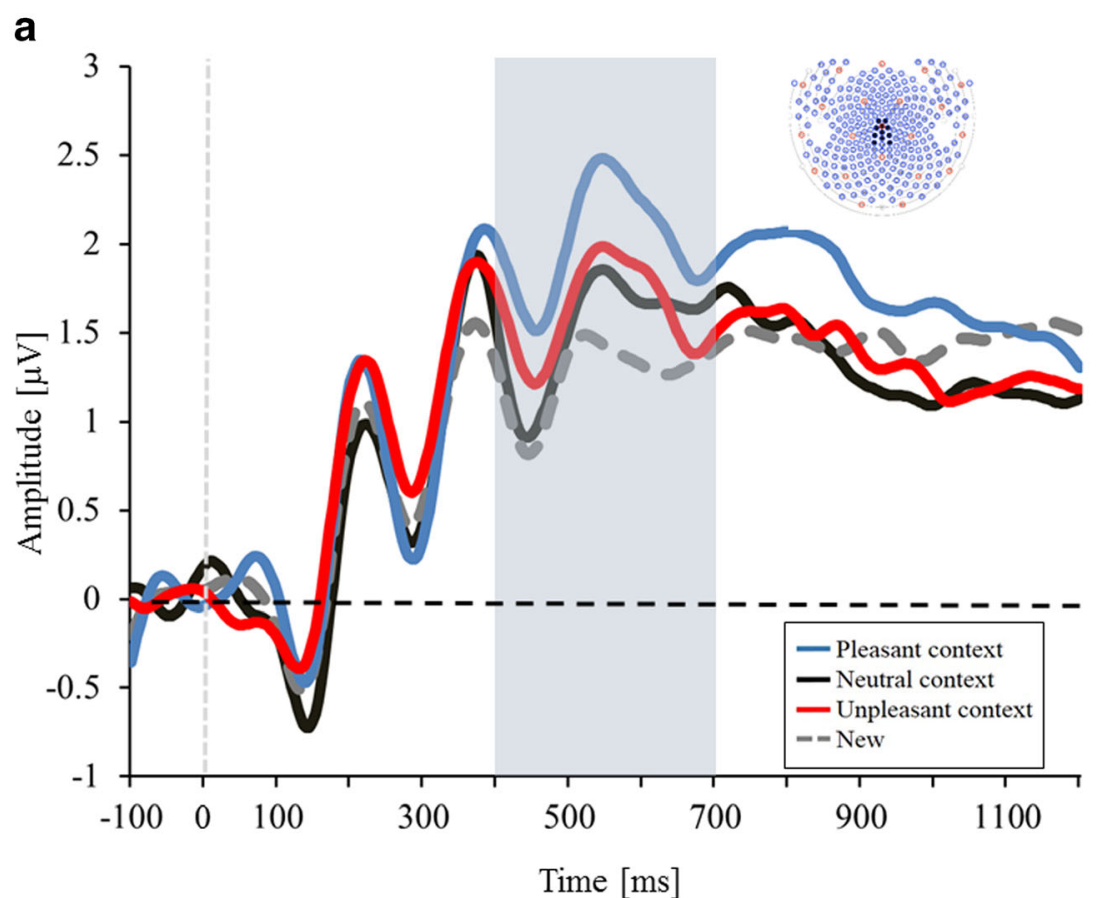

\section{b}

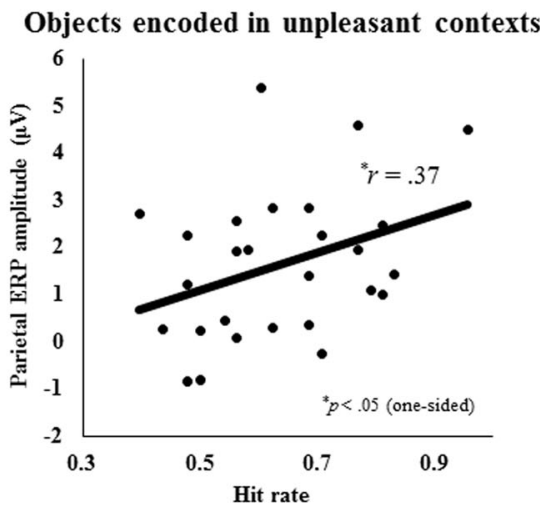

C Scalp Differences (400-700 ms)

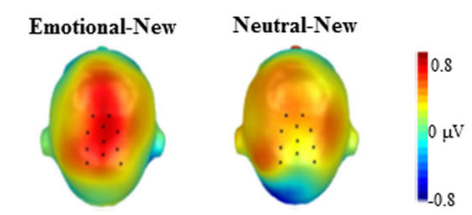

Fig. 3 Parietal ERP effect. A: Grand average ERPs evoked by correctly recognized new (gray dotted line) and old objects encoded in pleasant (blue), neutral (black), and unpleasant (red) contexts. The waveforms represent the ERPs averaged across electrodes within a centro-parietal sensor cluster. B: Correlation between the mean amplitude of the parietal

ERP positivity (400-700 ms) and hit rate for objects encoded in unpleasant contexts. C: Display of the scalp topographies of the ERP old/new differences (objects in emotional contexts and neutral contexts vs. new objects). (Color figure online)

26) $=12.12, p<.005, \eta_{\mathrm{p}}{ }^{2}=.32$. This old $/$ new difference was modulated by encoding context, $F(2,52)=3.14, p=.05, \eta_{\mathrm{p}}{ }^{2}=$ .11. Specifically, objects paired with emotional backgrounds elicited a larger ERP positivity than novel objects: unpleasant contexts vs. new objects, $F(1,26)=4.52, p<.05, \eta_{\mathrm{p}}{ }^{2}=.15$, (pleasant contexts vs. new objects): $F(1,26)=24,74, p<.001$, $\eta_{\mathrm{p}}{ }^{2}=.49$. However, objects paired with neutral background scenes did not show the parietal old/new effect: neutral contexts vs. new objects, $F(1,26)=1.53, p=.23, \eta_{\mathrm{p}}{ }^{2}=.06$ (see Fig. 3C).

Correlations between recognition performance and ERP effects Significant correlations between hit rate performance and ERPs were only observed for unpleasant contexts in the 180 to $220 \mathrm{~ms}, 300$ to $500 \mathrm{~ms}$ (see Fig. 2B), and 400 to $700 \mathrm{~ms}$ (see Fig. 3B) time window. Hit rates for objects encoded in unpleasant contexts showed a positive relation with the ERP amplitude (180-220 ms, $r=.37, p=.03$, one-tailed; 300$500 \mathrm{~ms}, r=.43, p<.05 ; 400-700 \mathrm{~ms}, r=.35, p=.035$, onetailed), suggesting that higher memory accuracy was related to larger positivity for objects encoded in the unpleasant context (see Fig. 2B, Fig. 3B). This relation was not found for objects encoded with pleasant or neutral contexts in either time windows $(r \mathrm{~s}<.27, p \mathrm{~s}>.17)$.

\section{Discussion}

In the current study, ERPs were used to investigate long-term recognition memory for neutral objects that had been encoded in an emotionally arousing or neutral context. We found that ERPs during retrieval were sensitive to context differences at encoding at three different time windows. We observed that old objects previously paired with emotional contexts prompted an enhanced early (180-220 ms) positivity (P2) over frontal sites. Furthermore, correct recognition was associated with larger centro-parietal ERP old/new differences (400-700 ms) for objects encoded in both pleasant and unpleasant but not in neutral contexts and associated with early frontal ERP old/new differences (300-500 ms), particularly for unpleasant contexts. Our results indicate that emotion improves associative binding and engages both automatic perceptual mechanisms and explicit recognition processes at retrieval, such as familiarity and recollection processes.

Although the effect was only marginal in the current experiment, we found enhanced memory performance for neutral objects associated with emotional contexts, in comparison to neutral contexts. This finding is in line with many previous studies reporting emotional memory-enhancing effects for single items and contexts (Bradley et al., 1992; Doerksen \& Shimamura, 2001; Dolcos et al., 2005; Guillet \& Arndt, 2009; 
Jaworek et al., 2014; Maratos \& Rugg, 2001; Mather \& Nesmith, 2008; Nashiro \& Mather, 2011; Pierce \& Kensinger, 2011; Smith, Dolan, et al., 2004; Weymar et al., 2009, 2010b, 2011; Weymar Löw, Modess, et al., 2010a; Wirkner et al., 2013, 2015; but see Jaeger et al., 2009; Jaeger \& Rugg. 2012), suggesting that emotional arousal improves long-term associative memory.

In ERPs, correctly recognized old items compared to correctly classified new items elicited enhanced ERP positivity, replicating a large body of previous work on memory research with short and long retention intervals (e.g., Rugg, Mark, Walla, Schloerscheidt, Birch, \& Allan, 1998; see for reviews Rugg \& Curran, 2007; Weymar \& Hamm, 2013). As expected, larger ERP old/new differences were observed for neutral objects encoded in emotionally arousing, but not in emotionally neutral contexts over parietal regions. Because a parietal ERP old/new effect has been related to the process of contextual remembering (Wilding, 2000; Wilding \& Rugg, 1996; see Rugg \& Curran, 2007, for review), our finding indicates that retrieval of emotional (unpleasant and pleasant) contexts engages recollection processes. This clearly replicates previous ERP picture memory studies that found enhanced parietal ERP old/new effects for emotional pictures (e.g., Ferrari, Bradley, Codispoti, Karlsson, \& Lang, 2013; Jaworek et al., 2014; Weymar et al., 2009; Weymar et al., 2010b, 2011; Wirkner et al., 2013, 2015). Interestingly, our result contrasts with prior work where comparable ERP old/new effects were found when using emotional and neutral pictures as contexts (Jaeger et al., 2009; Jaeger \& Rugg, 2012; Smith, Dolan, et al., 2004). One reason for this discrepancy could be related to item-context binding processes (Mackay et al., 2004; Mather, 2007), which were facilitated methodologically in the present study. It has been observed that contextual memory increases when neutral items are well integrated with other items or contexts (Murray \& Kensinger, 2012, 2013), especially when the latter are arousing (Guillet \& Arndt, 2009; Pierce \& Kensinger, 2011). Compared to previous studies (e.g., Jaeger \& Rugg, 2012), we facilitated item-context pairing by integrating the object into the scene.

Another reason that might be critical is stimulus order presentation (Sakaki, Fryer, \& Mather, 2014; Sutherland \& Mather, 2012). Based on the ABC theory (Mather \& Sutherland, 2011), recent studies have observed that emotionally arousing stimuli distinctly modulate memory for preceding and following neutral target stimuli (Sakaki et al., 2014; Sutherland \& Mather, 2012). Thus, if emotional events are preceded by a neutral target stimulus (i.e., high priority), emotional arousal further enhances memory for highly prioritized neutral items; however, if the emotional event is followed by a neutral target stimulus, emotional arousal captures attentional resources and impairs perceptual processing of the neutral target item, hindering the memory-enhancing effects (Sakaki et al., 2014; Sutherland \& Mather, 2012). Contrary to prior studies (e.g., Jaeger et al., 2009; Jaeger \& Rugg, 2012), we intended to avoid competition for attention resources by presenting the object before the context image appeared.

However, most critically contributing to the emotional enhancing effects observed in the present data is probably the 1week interval between the encoding and the retrieval session. A number of studies have demonstrated that longer retention periods facilitate consolidation processes, resulting in memory-enhancing effects (e.g., LaBar \& Cabeza, 2006), especially for emotionally, compared to neutral, arousing events (e.g., Dolcos et al., 2005; Pierce \& Kensinger, 2011; Weymar et al., 2009; see Weymar \& Hamm, 2013, for review). In contrast to a number of previous emotional associative memory studies (e.g., Smith, Dolan, et al., 2004; Maratos \& Rugg, 2001; Jaeger et al., 2009), we promoted consolidation processes by means of long retention periods.

To summarize, the ERP parietal old/new effect findings seem to indicate that emotional contexts enhance electrophysiological correlates of long-term recollection memory for integrated neutral material. In addition to the parietal ERP old/ new effects, emotional context modulated frontal ERP correlates of familiarity-based recognition. Compared to pleasant and neutral contexts, objects embedded in unpleasant background scenes generated enhanced frontal ERP old/new differences between 300 and $500 \mathrm{~ms}$. A number of studies propose that relational memory depends upon recollection-based mechanisms (Rugg \& Curran, 2007; Wilding \& Rugg, 1996). However, recent behavioral (Diana, Yonelinas, \& Ranganath, 2008, 2010) and electrophysiological studies (Addante, Raganath, \& Yonelinas, 2012; Diana, Van den Boom, Yonelinas, \& Ranganath, 2011; Ecker, Zimmer, \& GrohBordin, 2007a, b; Mollison \& Curran, 2012; Peters \& Daum, 2009; Speer \& Curran, 2007; Tibon, Ben-Zvi, \& Levy, 2014; Tibon, Gronau, Scheuplein, Mecklinger, \& Levy, 2014; Tibon \& Levy, 2014; Tsivilis et al., 2001; Zheng, Li, Xiao, Broster, \& Jiang, 2015) have found that familiarity-related processes could also contribute to source recognition (Johnson, Hashtroudi, \& Lindsay, 1993; Yonelinas, 2002). In an attempt to shed light on the familiarrelated processes embedded in source memory, Diana et al. (2008, 2010; Diana et al., 2011) investigated the impact of encoding processes on familiarity-based recognition. The authors observed that exclusively high-unitized associationsthat is, item-context pairings encoded as a single unit-elicited frontal ERP old/new effects, whereas low-unitized associations only elicited recollection-related ERPs (Diana et al., 2011). In the same direction, a number of studies have observed that when item-source associations can be processed together at encoding, familiarity processes are also enhanced during recognition. Thus, when item and source information are encoded in the same modality (visual) vs. different modality (visual and auditory; Tibon, Ben-Zvi, et al., 2014; Tibon, Gronau, et al., 2014; Tibon \& Levy, 2014), when the nature of 
the association item-source is intrinsic versus extrinsic (Ecker et al., 2007a, b; Zheng et al., 2015), or when source refers to salient contextual information (Mollison \& Curran, 2012), source recognition prompts larger familiarity-related ERPs, suggesting that memory for source information is strengthened (Addante et al., 2012; Chiu et al., 2013; Curran, 2004). In the present study, no explicit instructions for unitization were given; however, as commented above, we promoted item-context binding processes at encoding. It might be that this instruction accentuated item-context unitization for unpleasant associations and thus promoted stronger familiaritybased recognition of negative source information. However, clear conclusions cannot be derived because judgments regarding the strength of the associations were not directly recorded in the present study. Future research should assess the emotional effect on strength/unitization of item-context associations in order to clarify the present finding.

Intriguingly, we found differences of context association at early stages of processing. Neutral stimuli encoded in emotional compared to neutral contexts elicited a larger early (180-220 ms) positive-going waveform over frontal sites. This early emotional effect resembles those reported by previous source memory studies (Jaeger et al., 2009; Jaeger \& Rugg, 2012; Smith, Dolan, et al., 2004), suggesting that neutral stimuli acquired emotionally arousing properties. This emotion effect may relate to the transmission of emotional attributes from contexts to objects by means of associative binding mechanisms (Smith, Dolan, et al., 2004), enhancing their processing (e.g., Öhman \& Mineka, 2001; Vuilleumier, 2005). A substantial body of research has suggested the existence of highly elaborated networks, involving the amygdala (Öhman \& Mineka, 2001) and cortical regions (Pessoa \& Adolphs, 2010; Van Gaal \& Lamme, 2012) that rapidly identify motivationally relevant events (Brosch, Sander, Pourtois, \& Scherer, 2008; Pourtois, Grandjean, Sander, \& Vuilleumier, 2004; Steinberg, Bröckelmann, Rehbein, Dobel, \& Junghöfer, 2013; Wieser et al., 2014) and further provide a rapid learning capacity (cf. Steinberg et al., 2013). Thus, our data seem to indicate that neutral objects embedded in emotional contexts have rapidly - after two pairings! - acquired long-lasting emotional relevance.

An alternative but not excluding interpretation could also link the early frontal ERP with memory-related mechanisms. The frontal P2 has been related to the activation of representations retrieved in long-term memory due to the detection of visual information (Curran \& Dien, 2003; Tsivilis et al., 2001; Voss \& Paller, 2009) under explicit memory testing (Curran, 1999; Voss \& Paller, 2009; but see Jaeger \& Rugg, 2012). Specifically, it has been observed that the frontal P2 increases when the visual input matches with efficiently stored information, suggesting that the extent of activation of representations in memory indexed by P2 might relate to the phenomenological salience of the stimuli (cf. Voss \& Paller, 2009).
Consistent with this idea, Schaefer et al. (2011) found that frontal P2 was modulated by the memory strength of emotional events; that is, remembered unpleasant scenes-but not neutral ones - evoked frontal P2 old/new effects; moreover, P2 amplitudes in response to unpleasant images increased with their arousal. In the current study, larger P2 was evoked by neutral objects embedded in emotional compared to neutral background scenes, suggesting that emotional contexts increase the saliency of the events bound with, facilitating their later recognition.

From a dual-process model perspective (Yonelinas, 2002), however, it remains unclear which mnemonic mechanisms underlie the P2 old/new effects. On the one hand, the spatiotemporal attributes of the P2 matches with the frontal familiarity-related old/new effects, suggesting the existence of similar processes between both components. On the other hand, the P2 old/new effect has only been found when the events where labeled as remembered but not when they were considered familiar (Voss \& Paller, 2009), indicating that P2 might be related to recollection. Schaefer et al. (2011) found distinct patterns of modulation across arousal levels between P2, frontal and parietal old/new effects, suggesting that different memory subprocesses might be involved for each component (cf. Schaefer et al., 2011). We, however, did not find clear evidence that would allow us to disentangle this question. Future research should focus on elucidating the memory sub-processes underlying this frontal memory index, assessing, for instance, which recognition processes (remember vs. know) have been employed.

Surprisingly, we found that correctly identified new objects also elicited a larger P2 than old objects paired with neutral background scene. A plausible explanation of this effect could be that early frontal activity is related to the processing of novelty/relevant stimuli (Tibon, Gronau, et al., 2014b; Tsivilis et al., 2001; Voss \& Paller, 2009). In this line, Ecker, Zimmer, Groh-Bordin, and Mecklinger (2007) observed that novel neutral events generated larger early frontal activity than correctly recognized old neutral stimuli. These authors suggest that the brain response difference between new and old information at early stages of processing might be associated with an enhanced attentional capture (Ecker et al., 2007a). Thus, based on previous research, we interpret this finding as a result of enhanced processing of new objects, along with decreased processing of relatively nonrelevant (associated with neutral source information) old events.

Although pleasant and unpleasant background scenes were matched in terms of emotional arousal, we found that frontal old/new effects were only present for unpleasant-related associations. We further observed that memory performance for objects paired with unpleasant background scenes predicted larger electrophysiological activity at the three ERP memoryrelated components ( $\mathrm{P} 2$, frontal and parietal old/new effects). These results are in line with recent memory studies that report 
enhanced long-term explicit memory for unpleasant-related stimuli, compared to pleasant ones (Pierce \& Kensinger, 2011; Ochsner, 2000; Weymar et al., 2011). For instance, Pierce and Kensinger investigated emotional valence and arousal on associative binding after a short (15-min) and longer (1-week) delay and observed that memory performance for unpleasant word pairs was better in comparison to pleasant and neutral word pairs after long, but not after short retention intervals, suggesting that unpleasant-related stimuli acquire a higher long-term relevance. From an evolutionary perspective, memory for stimuli related to potentially dangerous events should be consistent, salient, and stable over time in order to facilitate their detection and avoid them in the future (Dolan, 2002). Furthermore, it has been suggested that pleasant contexts (animals or nurture scenes) do not contain the same type of survival-relevant information as unpleasant contexts (accidents or attacks), making them less relevant for future purposes than negative situations (Ashby, Isen, \& Turcken, 1999; Fredrickson, 1998, 2001; Ochsner, 2000). Thus, the current findings may indicate that especially unpleasant contexts facilitate associative long-term memory processes.

One further interpretation of the present results might be related to postencoding arousal effects (Anderson, Wais, \& Gabrieli, 2006; Knight \& Mather, 2009) that might have facilitated memory for neutral objects. Some studies have observed that presenting neutral stimuli shortly prior to emotionally arousing materials can result in enhanced memory (1week later) for the preceding event (Anderson et al., 2006). A potential mechanism might be that stress hormones (rapid nongenomic effects of catecholamines and glucocorticoids) released in response to arousing emotional contexts might increase vigilance via interactions between the amygdala and hippocampus formation (e.g., McGaugh, 2013), and facilitate memory storage for the context itself but also for recently experienced-related events.

Although the ability to remember cues associated with potentially threatening events could protect us from dramatic consequences, when these events are extremely distressing, memories can become maladaptive and clinically relevant (Ehlers \& Clark, 2000). For instance, in patients suffering from posttraumatic stress disorder (PTSD), events associated with traumatizing contexts can involuntarily trigger vivid distressing memories in the form of intrusive thoughts, flashbacks, or nightmares (Parson \& Ressler, 2012) and, on the other hand, can result in impaired episodic memory for the traumatic event itself (e.g., Brewin, 2013; Flor \& Nees, 2014; Hayes, VanElzakker, \& Shin, 2012; McNally, 2008; Wilker, Elbert, \& Kolassa, 2014). A prominent hypothesis of PTSD etiology suggests that trauma memories are poorly integrated into their context (e.g., time and place) during encoding, thus resulting in retrieval distortions of trauma-related information (Dolcos, 2013; Pannu Hayes et al., 2011), overgeneralization and easy triggering of physically similar cues (Ehlers \& Clark, 2000), which might relate to deficits in long-term contextual binding processes. Despite its relevance, little is known about the neural processing of emotional binding mechanisms in PTSD. ERPs might be a useful tool to elucidate the longterm binding deficits in PTSD, providing new insights into the neurobiological alterations of the memory systems in trauma and stress-related disorders.

\section{Conclusion}

In summary, we found that neutral information can activate long-term memories due to their emotional associations. Neutral objects encoded in emotional contexts showed prioritized automatic perceptual and explicit mnemonic processing during recognition that was also related to long-term memory performance. Our findings highlight the importance of emotional binding mechanisms in long-term memory processes, which could have also direct clinical relevance for trauma- and stressor-related disorders.

Acknowledgments This research was supported by a grant from the German Research Foundation (DFG, WE 4801/3-1) to Mathias Weymar at the University of Greifswald. Carlos Ventura-Bort (E-2013-15) was supported by the program for international stays of the Universitat Jaume I of Castellón, Spain. We are grateful to Laura Troike, Karen Giersberg, and Inga Damerow for their assistance in data collection.

\section{References}

Addante, R. J., Ranganath, C., \& Yonelinas, A. P. (2012). Examining ERP correlates of recognition memory: Evidence of accurate source recognition without recollection. NeuroImage, 62(1), 439-450. doi: 10.1016/j.neuroimage.2012.04.031

Anderson, A., Wais, P., \& Gabrieli, J. D. E. (2006). Emotion enhances remembrance of neutral events past. Proceedings of the National Academy of Sciences, USA, 103, 1599-1604. doi:10.1073/pnas. 0506308103

Ashby, F. G., Isen, A. M., \& Turken, U. (1999). A neuropsychological theory of positive affect and its influence on cognition. Psychological Review, 106(3), 529-550. doi:10.1037/0033295x. 106.3.529

Awipi, T., \& Davachi, L. (2008). Content-specific source encoding in human medial temporal lobe. Journal of Experimental Psychology: Learning, Memory, and Cognition, 34, 769-779. doi: 10.1037/0278-7393.34.4.769

Bisby, J. A., \& Burgess, N. (2014). Negative affect impairs associative memory but not item memory. Learning and Memory, 21, 760-766. doi:10.1101/lm.032409.113

Bradley, M. M., Greenwald, M. K., Petry, M. C., \& Lang, P. J. (1992). Remembering pictures: Pleasure and arousal in memory. Journal of Experimental Psychology: Learning, Memory, and Cognition, 18(2), 379-390. doi:10.1037/0278-7393.18.2.379

Brewin, C. R. (2013). Episodic memory, perceptual memory, and their interaction: Foundations for a theory of posttraumatic stress disorder. Psychological Bulletin, 140(1), 69-97. doi:10.1037/a0033722 
Brodeur, M. B., Dionne-Dostie, E., Montreuil, T., \& Lepage, M. (2010). The bank of standardized stimuli (BOSS), a new set of 480 normative photos of objects to be used as visual stimuli in cognitive research. PLoS ONE, 5(5), e10773. doi:10.1371/journal.pone. 0010773

Brosch, T., Sander, D., Pourtois, G., \& Scherer, K. R. (2008). Beyond fear: Rapid spatial orienting toward positive emotional stimuli. Psychological Science, 19(4), 362-370. doi:10.1111/j.1467-9280. 2008.02094.X

Chiu, Y. C., Dolcos, F., Gonsalves, B. D., \& Cohen, N. J. (2013). On opposing effects of emotion on contextual or relational memory. Frontiers in Psychology, 4, 103. doi:10.3389/fpsyg.2013.00103

Curran, T. (1999). The electrophysiology of incidental and intentional retrieval: ERP old/new effects in lexical decision and recognition memory. Neuropsychologia, 37, 771-785. doi:10.1016/S00283932(98)00133-X

Curran, T. (2004). Effects of attention and confidence on the hypothesized ERP correlates of recollection and familiarity. Neuropsychologia, 42, 1088-1106. doi:10.1016/j.neuropsychologia.2003.12.011

Curran, T., \& Dien, J. (2003). Differentiating amodal familiarity from modality-specific memory processes. An ERP study. Psychophysiology, 40, 979-988. doi:10.1111/1469-8986.00116

Davachi, L. (2006). Item, context and relational episodic encoding in humans. Current Opinion in Neurobiology, 16(6), 693-700. doi: 10.1016/j.conb.2006.10.012

Diana, R. A., Van den Boom, W., Yonelinas, A. P., \& Ranganath, C. (2011). ERP correlates of source memory: Unitized source information increases familiarity-based retrieval. Brain Research, 1367, 278-286. doi:10.1016/j.brainres.2010.10.030

Diana, R. A., Yonelinas, A. P., \& Ranganath, C. (2008). The effects of unitization on familiarity-based source memory: Testing a behavioral prediction derived from neuroimaging data. Journal of Experimental Psychology Learning Memory and Cognition, 34, 730-740. doi:10.1037/0278-7393.34.4.730

Diana, R. A., Yonelinas, A. P., \& Ranganath, C. (2010). Medial temporal lobe activity during source retrieval reflects information type, not memory strength. Journal of Cogitive Neuroscience, 22, 18081818. doi:10.1162/jocn.2009.21335

Doerksen, S., \& Shimamura, A. P. (2001). Source memory enhancement for emotional words. Emotion, 1(1), 5-11. doi:10.1037/1528-3542. 1.1.5

Dolan, R. J. (2002). Emotion, cognition, and behavior. Science, 298, 1191-1194. doi: $10.1126 /$ science. 1076358

Dolcos, F. (2013). Linking enhancing and impairing effects of emotion: The case of PTSD. Frontiers in Integrative Neuroscience, 7(26). doi:10.3389/fnint.2013.00026

Dolcos, F., Denkova, E., \& Dolcos, S. (2012). Neural correlates of emotional memories: A review of evidence from brain imaging studies. Psychologia, 55(2), 80-111. doi:10.2117/psysoc.2012.80

Dolcos, F., LaBar, K. S., \& Cabeza, R. (2005). Remembering one year later: Role of the amygdala and the medial temporal lobe memory system in retrieving emotional memories. Proceedings of the National Academy of Sciences of the United States of America, 102(7), 2626-2631. doi:10.1073/pnas.0409848102

Ecker, U. K. H., Zimmer, H. D., Groh-Bordin, C., \& Mecklinger, A. (2007a). Context effects on familiarity are familiarity effects of context: An electrophysiological study. International Journal of Psychophysiology, 64, 146-156. doi:10.1016/j.ijpsycho.2007.01. 005

Ecker, U. K. H., Zimmer, H. D., \& Groh-Bordin, C. (2007b). Color and context: An ERP study on intrinsic and extrinsic feature binding in episodic memory. Memory and Cognition, 35(6), 1483-1501.

Ehlers, A., \& Clark, D. M. (2000). A cognitive model of post traumatic stress disorder. Behaviour Research and Therapy, 38, 319-345. doi: 10.1016/S0005-7967(99)00123-0
Ferrari, V., Bradley, M. M., Codispoti, M., Karlsson, M., \& Lang, P. J. (2013). Repetition and brain potentials when recognizing natural scenes : Task and emotion differences. Social Cognitive and Affective Neuroscience, 8(8), 847-854. doi:10.1093/scan/nss081

Flor, H., \& Nees, F. (2014). Learning, memory and brain plasticity in posttraumatic stress disorder: Context matters. Restorative Neurology and Neuroscience, 32(1), 95-102. doi:10.3233/RNN139013

Fredrickson, B. L. (1998). What good are positive emotions? Review of General Psychology, 2(3), 300-319. doi:10.1037/1089-2680.2.3. 300

Fredrickson, B. L. (2001). The role of positive emotions in positive psychology: The broaden-and-build theory of positive emotions. American Psychologist, 56(3), 218-226. doi:10.1037/0003-066X. 56.3.218

Guillet, R., \& Arndt, J. (2009). Taboo words: The effect of emotion on memory for peripheral information. Memory \& Cognition, 37(6), 866-879. doi:10.3758/MC.37.6.866

Hayes, J. P., VanElzakker, M. B., \& Shin, L. M. (2012). Emotion and cognition interactions in PTSD: A review of neurocognitive and neuroimaging studies. Frontiers in Integrative Neuroscience, 6, 89. doi:10.3389/fnint.2012.00089

Jaeger, A., Johnson, J. D., Corona, M., \& Rugg, M. D. (2009). ERP correlates of the incidental retrieval of emotional information: Effects of study-test delay. Brain Research, 1269, 105-113. doi: 10.1016/j.brainres.2009.02.082

Jaeger, A., \& Rugg, M. D. (2012). Implicit effects of emotional contexts: An ERP study. Cognitive, Affective, \& Behavioral Neuroscience, 12(4), 748-760. doi:10.3758/s13415-012-0110-1

Jaworek, A., Weymar, M., Löw, A., \& Hamm, A. O. (2014). Brain potentials reflecting spontaneous retrieval of emotional long-term memories. Cognitive Neuroscience, 9, 1-9. doi:10.1080/17588928. 2014.916259

Johnson, M. K., Hashtroudi, S., \& Lindsay, D. S. (1993). Source monitoring. Psychological Bulletin, 114, 3-28. doi:10.1037/0033-2909. 114.1.3

Junghöfer, M., Elbert, T., Tucker, D. M., \& Rockstroh, B. (2000). Statistical control of artifacts in dense array EEG/MEG studies. Psychophysiology, 37(4), 523-532. doi:10.1111/1469-8986. 3740523

Knight, M., \& Mather, M. (2009). Reconciling findings of emotioninduced memory enhancement and impairment of preceding items. Emotion, 9(6), 763-781. doi:10.1037/a0017281

Koenig, S., \& Mecklinger, A. (2008). Electrophysiological correlates of encoding and retrieving emotional events. Emotion, 8, 162-173. doi:10.1037/1528-3542.8.2.162

LaBar, K. S., \& Cabeza, R. (2006). Cognitive neuroscience of emotional memory. Nature Reviews Neuroscience, 7(1), 54-64. doi:10.1038/ nrn 1825

Lang, P. J., Bradley, M. M., \& Cuthbert, B. N. (2008). International affective picture system (IAPS): Affective ratings of pictures and instruction manual (Technical Report No. A-8). Gainesville: University of Florida.

MacKay, D. G., Shafto, M., Taylor, J. K., Marian, D. E., Abrams, L., \& Dyer, J. R. (2004). Relations between emotion, memory, and attention: Evidence from taboo Stroop, lexical decision, and immediate memory tasks. Memory \& Cognition, 32, 474-488. doi:10.3758/ BF03195840

Maratos, E. J., \& Rugg, M. D. (2001). Electrophysiological correlates of the retrieval of emotional and non-emotional context. Journal of Cognitive Neuroscience, 13(7), 877-891. doi:10.1162/ 089892901753165809

Mather, M. (2007). Emotional arousal and memory binding: An objectbased framework. Perspectives on Psychological Science, 2(1), 33 52. doi:10.1111/j.1745-6916.2007.00028.x 
Mather, M., \& Nesmith, K. (2008). Arousal-enhanced location memory for pictures. Journal of Memory and Language, 58(2), 449-464. doi:10.1016/j.jml.2007.01.004

Mather, M., \& Sutherland, M. R. (2011). Arousal-biased competition in perception and memory. Perspectives on Psychological Science, 6(2), 114-133. doi:10.1177/1745691611400234

McGaugh, J. L. (2004). The amygdala modulates the consolidation of memories of emotionally arousing experiences. Annual Review of Neuroscience, 27, 1-28. doi:10.1146/annurev.neuro.27.070203. 144157

McGaugh, J. L. (2013). Making lasting memories: Remembering the significant. Proceedings, National Academy of Sciences, 110(2), 10401-10407. doi:10.1073/pnas. 1301209110

McNally, R. J. (2008). Panic and posttraumatic stress disorder: Implications for culture, risk, and treatment. Cognitive Behavior Therapy, 37(2), 131-134. doi:10.1080/16506070801969120

Mollison, M. V., \& Curran, T. (2012). Familiarity in source memory. Neuropsychologia, 50(11), 2546-2565. doi:10.1016/j. neuropsychologia.2012.06.027

Moreno-Martínez, F. J., \& Montoro, P. R. (2012). An ecological alternative to Snodgrass \& Vanderwart: 360 high quality colour images with norms for seven psycholinguistic variables. PLoS ONE, 7(5), e37528. doi:10.1371/journal.pone.0037527

Murray, B. D., \& Kensinger, E. A. (2012). The effects of emotion and encoding strategy on associative memory. Memory \& Cognition, 40, 1056-1069. doi:10.3758/s13421-012-0215-3

Murray, B. D., \& Kensinger, E. A. (2013). A review of the neural and behavioral consequences for unitizing emotional and neutral information. Frontier in Behavioral Neuroscience, 7, 42. doi:10.3389/ fnbeh.2013.00042

Nashiro, K., \& Mather, M. (2011). How arousal affects younger and older adult's memory binding. Experimental Aging Research, 37(1), 108128. doi:10.1080/0361073X.2011.536746

Ochsner, K. N. (2000). Are affective events richly recollected or simply familiar? The experience and process of recognizing feelings past. Journal of Experimental Psychology: General, 129, 242-261. doi: 10.1037/0096-3445.129.2.242

Öhman, A., \& Mineka, S. (2001). Fears, phobias, and preparedness: Toward an evolved module of fear and fear learning. Psychological Review, 108(3), 483-522. doi:10.1037//0033-295X. 108.3.483

Pannu Hayes, J., LaBar, K. S., McCarthy, G., Selgrade, E., Nasser, J., Dolcos, F., . . . Morey, R. A (2011). Reduced hippocampal and amygdala activity predicts memory distortions for trauma reminders in combat-related PTSD. Journal of Psychiatric Research, 45(5), 660-669. doi:10.1016/j.jpsychires.2010.10.007

Parsons, R. G., \& Ressler, K. J. (2012). Implications of memory modulation for post-traumatic stress and fear disorders. Nature Neuroscience, 16(2), 146-153. doi:10.1038/nn.3296

Pessoa, L., \& Adolphs, R. (2010). Emotion processing and the amygdala: From a "low road" to "many roads" of evaluating biological significance. Nature Reviews Neuroscience, 11(11), 773-783. doi:10. $1038 /$ nrn2920

Peters, J., \& Daum, I. (2009). Frontal but not parietal positivity during source recollection is sensitive to episodic content. Neuroscience Letters, 454, 182-186. doi:10.1016/j.neulet.2009.03.019

Peyk, P., De Cesarei, A., \& Junghöfer, M. (2011). ElectroMagnetoEncephaloGraphy Software: Overview and integration with other EEG/MEG toolboxes. Computational Intelligence and Neuroscience, 2011, 861705. doi:10.1155/2011/861705

Pierce, B. H., \& Kensinger, E. A. (2011). Effects of emotion on associative recognition: Valence and retention interval matter. Emotion, 11, 139-144. doi:10.1037/a0021287

Pourtois, G., Grandjean, D., Sander, D., \& Vuilleumier, P. (2004). Electrophysiological correlates of rapid spatial orienting towards fearful faces. Cerebral Cortex, 14(6), 619-633. doi:10.1093/ cercor/bhh023

Quevedo, J., Sant' Anna, M. K., Madruga, M., Lovato, I., de-Paris, F., Kapczinski, F., ... Cahill, L. (2003). Differential effects of emotional arousal in short- and long-term memory in healthy adults. Neurobiology of Learning and Memory, 79, 132-135. doi:10. 1016/S1074-7427(02)00034-5

Ranganath, C. (2010). Binding items and contexts: The cognitive neuroscience of episodic memory. Current Directions in Psychological Science, 19(3), 131-137. doi:10.1177/0963721410368805

Rimmele, U., Davachi, L., Petrov, R., Dougal, S., \& Phelps, E. A. (2011). Emotion enhances the subjective feeling of remembering, despite lower accuracy for contextual details. Emotion, 11(3), 553-562. doi:10.1037/a0024246

Ritchey, M., Dolcos, F., \& Cabeza, R. (2008). Role of amygdala connectivity in the persistence of emotional memories over time: An eventrelated fMRI investigation. Cerebral Cortex, 18(11), 2494-2504. doi:10.1093/cercor/bhm262

Rugg, M. D., \& Curran, T. (2007). Event-related potentials and recognition memory. Trends in Cognitive Sciences, 11(6), 251-257. doi:10. 1016/j.tics.2007.04.004

Rugg, M. D., Mark, R. E., Walla, P., Schloerscheidt, A. M., Birch, C. S., \& Allan, K. (1998). Dissociation of the neural correlates of implicit and explicit memory. Nature, 392, 595-598. doi:10.1038/33396

Sakaki, M., Fryer, K., \& Mather, M. (2014). Emotion strengthens high priority memory traces but weakens low priority memory traces. Psychological Science, 25(2), 387-395. doi:10.1177/ 0956797613504784

Schaefer, A., Pottage, C. L., \& Rickart, A. J. (2011). Electrophysiological correlates of remembering emotional pictures. NeuroImage, 54(1), 714-724. doi:10.1016/j.neuroimage.2010.07.030

Sharot, T., Delgado, M. R., \& Phelps, E. A. (2004). How emotion enhances the feeling of remembering. Nature Neuroscience, 7, 13761380. doi: $10.1038 / \mathrm{nn} 1353$

Sharot, T., \& Phelps, E. A. (2004). How arousal modulates memory: Disentangling the effects of attention and retention. Cognitive, Affective, \& Behavioral Neuroscience, 4(3), 294-306. doi:10. 3758/cabn.4.3.294

Smith, A. P. R., Dolan, R. J., \& Rugg, M. D. (2004a). Event-related potential correlates of the retrieval of emotional and nonemotional context. Journal of Cognitive Neuroscience, 16(5), 760-775. doi:10. 1162/089892904970816

Smith, A. P. R., Henson, R. N. A., Dolan, R. J., \& Rugg, M. D. (2004b) fMRI correlates of the episodic retrieval of emotional contexts. NeuroImage, 22(2), 868-878. doi:10.1016/j.neuroimage.2004.01. 049

Smith, A. P. R., Henson, R. N. A., Rugg, M. D., \& Dolan, R. J. (2005). Modulation of retrieval processing reflects accuracy of emotional source memory. Learning \& Memory, 12, 472-479. doi:10.1101/ $1 \mathrm{~m} .84305$.effects

Speer, N. K., \& Curran, T. (2007). ERP correlates of familiarity and recollection processes in visual associative recognition. Brain Research, 1174, 97-109. doi:10.1016/j.brainres.2007.08.024

Steinberg, C., Bröckelmann, A. K., Rehbein, M., Dobel, C., \& Junghöfer, M. (2013). Rapid and highly resolving associative affective learning: Convergent electro- and magnetoencephalographic evidence from vision and audition. Biological Psychology, 92(3), 526-540. doi:10.1016/j.biopsycho.2012.02.009

Sutherland, M. R., \& Mather, M. (2012). Negative arousal amplifies the effects of saliency in short-term memory. Emotion, 12(6), 13671372. doi: $10.1037 / \mathrm{a} 0027860$

Tibon, R., Ben-Zvi, S., \& Levy, D. A. (2014a). Associative recognition processes are modulated by modality relations. Journal of Cognitive Neuroscience, 26(8), 1785-1786. doi:10.1162/jocn_a 00586

Tibon, R., Gronau, N., Scheuplein, A.-L., Mecklinger, A., \& Levy, D. A. (2014b). Associative recognition processes are modulated by the 
semantic unitizability of memoranda. Brain and Cognition, 92, 1931. doi:10.1016/j.bandc.2014.09.009

Tibon, R., \& Levy, D. A. (2014). The time course of episodic associative retrieval: Electrophysiological correlates of cued recall of unimodal and crossmodal pair-associate learning. Cognitive, Affective, \& Behavioral Neuroscience, 14, 220-235. doi:10.3758/s13415-0130199

Touryan, S. R., Marian, D. E., \& Shimamura, A. P. (2007). Effect of negative emotional pictures on associative memory for peripheral information. Memory, 15(2), 154-166. doi:10.1080/ 09658210601151310

Tsivilis, D., Otten, L. J., \& Rugg, M. D. (2001). Context effects on the neural correlates of recognition memory: An electrophysiological study. Neuron, 31(3), 497-505. doi:10.1016/S0896-6273(01) 00376-2

Van Gaal, S., \& Lamme, V. A. F. (2012). Unconscious high-level information processing: Implication for neurobiological theories of consciousness. The Neuroscientist, 18(3), 287-301. doi:10.1177/ 1073858411404079

Vidaurre, C., Sander, T. H., \& Schlögl, A. (2011). BioSig: The free and open source software library for biomedical signal processing. Computational Intelligence and Neuroscience, 2011, 935364. doi: $10.1155 / 2011 / 935364$

Voss, J. L., \& Paller, K. A. (2009). An electrophysiological signature of unconscious recognition memory. Nature Neuroscience, 12(3), 349-355. doi:10.1038/nn.2260

Vuilleumier, P. (2005). How brain beware: Neural mechanisms of emotional attention. Trends in Cognitive Sciences, 9(12), 585-594. doi: 10.1016/j.tics.2005.10.011

Weymar, M., \& Hamm, A. O. (2013). Electrophysiological signature of emotional memories. In M. Linden \& K. Rutkowski (Eds.), Hurting memories and beneficial forgetting (pp. 21-35). Burlington, MA: Elsevier Insights.

Weymar, M., Löw, A., Melzig, C., \& Hamm, A. O. (2009). Enhanced long-term recollection for emotional pictures: Evidence from highdensity ERPs. Psychophysiology, 46(6), 1200-1207. doi:10.1111/j. 1469-8986.2009.00869.x

Weymar, M., Löw, A., Modess, C., Engel, G., Gründling, M., Petersmann, A., Siegmund, W., Hamm, A. O. (2010a). Propranolol selectively blocks the enhanced parietal old/new effect during long-term recollection of unpleasant pictures: A high density
ERP study. NeuroImage, 49(3), 2800-2806. doi:10.1016/j. neuroimage.2009.10.025

Weymar, M., Löw, A., Schwabe, L., \& Hamm, A. O. (2010b). Brain dynamics associated with recollective experiences of emotional events. Neuroreport, 21(12), 827-831. doi:10.1097/WNR. 0b013e32833d180a

Weymar, M., Löw, A., \& Hamm, A. O. (2011). Emotional memories are resilient to time: Evidence from the parietal ERP old/new effect. Human Brain Mapping, 32(4), 632-640. doi:10.1002/hbm.21051

Wieser, M. J., Gerdes, A. B. M., Büngel, I., Schwarz, K. A., Mühlberger, A., \& Pauli, P. (2014). Not so harmless anymore: How context impacts the perception and electrocortical processing of neutral faces. NeuroImage, 92, 74-82. doi:10.1016/j.neuroimage.2014.01. 022

Wilding, E. L. (2000). In what way does the parietal ERP old/new effect index recollection? International Journal of Psychophysiology, 35(1), 81-87. doi:10.1016/S0167-8760(99)00095-1

Wilding, E. R., \& Rugg, M. D. (1996). An event-related potential study of recognition memory with and without retrieval of source. Brain, 199, 889-905. doi:10.1093/brain/119.3.889

Wilker, S., Elbert, T., \& Kolassa, I. T. (2014). The downside of strong emotional memories: How human memory-related genes influence the risk for posttraumatic stress disorder-A selective review. Neurobiology of Learning and Memory, 112, 75-86. doi:10.1016/j. $\mathrm{nlm} .2013 .08 .015$

Wirkner, J., Löw, A., Hamm, A. O., \& Weymar, M. (2015). Neurobiology of learning and memory new learning following reactivation in the human brain: Targeting emotional memories through rapid serial visual presentation. Neurobiology of Learning and Memory, 119, 63-68. doi:10.1016/j.nlm.2015.01.006

Wirkner, J., Weymar, M., Löw, A., \& Hamm, A. O. (2013). Effects of preencoding stress on brain correlates associated with the long-term memory for emotional scenes. PLoS ONE, 8(9), e68212. doi:10. 1371/journal.pone. 0068212

Yonelinas, A. P. (2002). The nature of recollection and familiarity: A review of 30 years of research. Journal of Memory and Language, 46(3), 441-517. doi:10.1006/jmla.2002.2864

Zheng, Z., Li, J., Xiao, F., Broster, L. S., \& Jiang, Y. (2015). Electrophysiological evidence for the effects of unitization on associative recognition memory in older adults. Neurobiological Learning and Memory, 121, 59-71. doi:10.1016/j.nlm.2015.03.006 